\title{
The Missing Foundation in Teacher Education: Knowledge of the Structure of Spoken and Written Language
}

\author{
Louisa Cook Moats \\ The Greenwood Institute \\ Putney, Vermont
}

Reading research supports the necessity for directly teaching concepts about linguistic structure to beginning readers and to students with reading and spelling difficulties. In this study, experienced teachers of reading, language arts, and special education were tested to determine if they have the requisite awareness of language elements (e.g., phonemes, morphemes) and of how these elements are represented in writing (e.g., knowledge of sound-symbol correspondences). The results were surprisingly poor, indicating that even motivated and experienced teachers typically understand too little about spoken and written language structure to be able to provide sufficient instruction in these areas. The utility of language structure knowledge for instructional planning, for assessment of student progress, and for remediation of literacy problems is discussed.

The teachers participating in the study subsequently took a course focusing on phonemic awareness training, spoken-written language relationships, and careful analysis of spelling and read-

\footnotetext{
Annals of Dyslexia, Vol. 44, 1994.

Copyright $\mathcal{C} 1994$ by The Orton Dyslexia Society ISSN 0736-9387
}

The author wishes to thank Susan Brady, Patricia Lindamood, Linda Rath and an anonymous reviewer for their very helpful comments on an earlier draft of this paper. Address for correspondence: P.O. Box 253, East Thetford, VT 05043. 
ing behavior in children. At the end of the course, the teachers judged this information to be essential for teaching and advised that it become a prerequisite for certification. Recommendations for requirements and content of teacher education programs are presented.

\section{Why Knowledge of Language is Necessary for Teachers}

In the last twenty years, volumes have been written about the linguistic processing deficits that characterize reading and spelling disabilities. The scientific community has reached consensus that most reading and spelling disabilities originate with a specific impairment of language processing, not with general visual-perceptual deficits, inability to construct meaning from context, or other more general problems with attention or memory (Adams 1990; Goswami and Bryant 1990; Gough, Ehri, and Treiman 1992; Stanovich 1991; Vellutino 1991a). More specifically, it is known that unskilled readers are unable to process efficiently and accurately the phonological building blocks of language and the units of print that represent them. Theoretical, experimental, and clinical evidence point to the necessity of helping unskilled readers and spellers acquire explicit knowledge of language structure. The findings of reading researchers, however, are likely to have little impact on practice unless practitioners can interpret and apply them. Consequently, the preparedness of teachers who must carry out linguistically informed, code-emphasis reading instruction is an increasingly important issue.

This paper will offer some evidence that graduate level teachers are typically undereducated for the very demanding task of teaching reading and spelling explicitly. It will document and give examples of common gaps in teachers' knowledge and awareness of language structure along with reasons those gaps may exist. Further, the importance of specific linguistic knowledge for instruction will be illustrated. Finally, the paper argues that policy changes are needed to improve the preparation and performance of literacy educators.

\section{The Nature of Reading and Spelling Disability}

Most children who are classified as having learning disabilities in public schools in fact have reading disabilities (Kavale and Forness 1985). Prevalence estimates of reading problems in the population of those with learning disabilities range from $75 \%$ to $85 \%$ nationwide. Although many of those with reading disabilities demonstrate varying degrees of language deficits in 
semantic and syntactic processing, most people with reading problems demonstrate a core deficit in phonological processing (Bryant and Bradley 1983; DeFries et al. 1991; Ehri 1993; Felton and Wood 1989; Goswami and Bryant 1990; Liberman and Shankweiler 1985; Stanovich 1991; Tunmer and Nesdale 1985; Vellutino and Scanlon 1987). Although phonological processing encompasses a number of linguistic skills, ${ }^{1}$ the most evident characteristic is a lack of phonological awareness: that is, lack of explicit awareness of the sound structure of words. Phonological awareness is measured by performance on a variety of tasks including phoneme counting (e.g., "How many sounds are in 'sheep'?"), phoneme identification (e.g., "What is the last sound in 'cab'?"), and phoneme deletion (e.g., "Say 'steak' without the $/ t / . ")$

Twenty years of research has consistently demonstrated that many beginning readers, and nearly all reading-disabled children, have difficulty on phonological awareness tasks (Adams 1990). Two points need to be made. First, phonological awareness normally develops over a number of years, progressing from early rhyming abilities to explicit awareness of the individual phonemes (see Bowey and Francis 1991, for a full discussion). Second, while learning to read enhances awareness of the sound structure of words, phonological awareness is distinct from either phonics or the ability to read and spell. A young pre-reader with no letter knowledge may nonetheless be able to perform a variety of listening activities such as rhyming, tapping out the number of syllables in a word, or listing words that begin with a certain sound. Indeed, inability to perform these tasks reveals a weak foundation for learning an alphabetic writing system. To be a skilled reader, one needs to appreciate that words are comprised of individual speech sounds that are more or less represented by letters. (In some instances, of course, single phonemes or speech sounds are spelled with more than one letter, as in th/r/ough; in other instances, a single phoneme such as long a is spelled in many different ways, e.g., eight, they, ate, say, gain.) Lacking the knowledge that letters or letter combinations correspond to speech sounds, the learner will find our writing system an enigma. Even as children begin to discover the sound-based nature of written words, and are able to identify

\footnotetext{
${ }^{1}$ Deficits in the ability to process and produce language at the level of phonology may be manifest on a variety of linguistic tasks, including word pronunciation (Catts 1989), word memory and retrieval (Wolf, Bally and Morris 1986), short-term memory for lists of words and numbers (Brady 1986), and reading nonsense words (Rack, Snowling and Olsen 1992).
} 
the initial sound in the word, they typically find the remainder unanalyzable, as witnessed by the child who writes the single letter "b" for "butterfly."

It is known, beyond doubt, that degree of awareness of the phonological structure of words is the best predictor of a child's subsequent reading success. At the same time, there have been promising developments in early intervention research. If a child is lacking in speech sound awareness, it can be taught directly as a precursor to and along with instruction in lettersound relationships (e.g., Ball and Blachman 1991; Yopp 1992). These findings imply that kindergarten, early elementary, and remedial classes need to incorporate direct instruction in the structure of language in order to provide the foundation children need to become skilled readers and spellers (see Brady, Fowler, Stone and Winbury, this volume, for discussion of training methods).

A second area of limited structural awareness for the beginning or poor reader/speller is appreciation of the morphemic structure of words. Morphemes are the smallest meaningful units in words. They may be whole words (e.g., foot, finger) or parts of words (e.g., un+teach+able; medic +al). Awareness of the morphemes in words facilitates both reading and spelling, and not only for the advanced reader. For example, beginning writers often spell plurals and past tense forms as they sound (e.g. $d \circ g z$, wakt), before they have grasped the plural concept represented by the consistent spelling " $s$," or the past tense concept represented by the consistent spelling "ed." Further, to progress to more advanced stages of reading and spelling, the learner must become aware that the spelling of meaningful word parts often stays constant even when pronunciation changes from one word form to another, as in compete and competition, resign and resignation, define and definition (Henry 1993; Moats and Smith 1992).

A related key finding in reading research is the importance of code-emphasis instruction for students who do not automatically learn to read and spell. It is beyond the scope of this paper to review the methods debate, but two points are important: inclusion of code-based instruction does not preclude welldesigned instruction in comprehension, and code-based instruction is not necessarily the "phonics" of old that was largely

\footnotetext{
2Spelling errors in general often reveal a student's limitations in phoneme awareness and phoneme identification. See Goswami, 1992; Lindamood, 1993; Moats, in press; and Treiman, 1993 for discussions of the relationship between phonological awareness and spelling.
} 
workbook oriented. When it is skillfully implemented, systematic code instruction is most effective for beginning and for problem readers (e.g., see Adams and Bruck 1993; Chall 1989; Liberman and Liberman 1990; and Mather 1992 for thoughtful, comprehensive reviews of the evidence). Effective instruction for beginning and for problem readers teaches them to be aware of speech sounds (phonemes) and how they are represented in the writing system (i.e., spelling-sound rules, syllable patterns) and of the meaningful units (morphemes) and their spelling patterns (Felton 1993; Juel 1988; Tunmer and Hoover 1993; Treiman and Baron 1983; Vellutino 1991b; Williams 1987). In fact, the research community is now focused on establishing a scientific base for refinements of code-emphasis intervention, including the most desirable unit of instruction (Adams 1990; Ehri and Robbins 1992; Gaskins et al. 1988; Goswami and Bryant 1990; Treiman 1992), the degree to which instruction should be systematic rather than incidental (Tunmer and Hoover 1993), and the timing and emphasis of such instruction in the curriculum (Calfee 1991).

Certainly, knowledge of the structure of language and the alphabetic writing system that represents it is not all that teachers must know in order to teach reading well. Nevertheless, given the evidence cited above, it is imperative that teachers have such knowledge to be successful with a range of learners. As will be elaborated in the discussion, the informed teacher will be able to present linguistic concepts accurately and with appropriate examples, and will be able to assess and interpret a student's stage of reading and spelling development based on direct observation of his or her performance.

In summary, practitioners now have a solid research foundation on which to base their instructional practices (Adams 1990). Better readers, who generally can be predicted to have good phonemic awareness, may need less explicit and intensive teaching to process spoken and written linguistic units, as they are often able to grasp structural relationships between written phonograms and words with exposure to just a few examples. Yet even these students may benefit from such instruction, showing more rapid progress and better spelling skills. On the other hand, it is now quite clear that poorer readers, depending on the severity of their lack of phonemic awareness, need remediation of this handicap and benefit from intensive, systematic exposure to examples and explicit teaching of linguistic concepts. Even if there are several paths to the same goal, teachers of those with reading/spelling difficulties must themselves have command of word parts, spoken and written, to be able to 
illustrate and interpret them for children. Unambiguous presentation of information requires detailed familiarity with phonemegrapheme correspondences and other units of word structure. Are we currently requiring teachers to have such a command of their language and the approaches that work with dyslexic children? Both indirect and direct evidence regarding teacher training suggests that we are not.

\section{Do We Prepare Teachers for Explicit Reading and Spelling Instruction?}

General Gaps in Teacher Education. The general insufficiency of teacher training in the area of reading and learning disabilities has been discussed in other sources. Nolen, McCutchen, and Berninger (1990), for example, concluded after surveying general teacher preparation in reading and writing instruction that program requirements and state certification standards must be upgraded nationwide. Teachers could not, in their estimation, be prepared to meet the diverse needs of students who are at risk for reading/writing failure on the basis of current, minimal requirements in teacher education, which range from no coursework in reading to an average of about 12 course hours. Lyon, Vaasen, and Toomey (1989), after surveying both regular and special education teachers' perceptions of their own training, argued more specifically that many training programs were inadequate. They found that both regular and special education teachers were lacking content expertise, knowledge of validated pedagogical principles, and supervised experience with diverse learners. Lyon et al. also characterized the teaching of reading and other basic academic skills as a job for an expert, a process that should involve deliberate selection of instructional content and strategies. To reach a satisfactory level of content knowledge and procedural expertise, teachers deserve intensive theoretical and practical training that needs to include demonstration and supervised practice.

Without adequate training, teachers' sense of efficacy in their jobs is most certainly diminished. Students are usually referred to special education when teachers feel they can not bring about desired outcomes with students (Soodak and Podell 1993; Zigmond 1993). Turnover in teaching is high; about fifty \% of teachers leave their jobs within five years. Commitment and longevity is greater, however, in those whose self-efficacy ratings are strong (Billingsley 1993). Many factors contribute to the erosion of efficacy, but the mismatch between teacher preparation and the expertise demanded by hard-to-teach children may be a significant contributor to this high rate of turnover. 
A recent survey of several hundred learning specialists in one mid-western state suggests the gaps that may exist between the content knowledge held by learning specialists and the language knowledge needed for teaching reading and writing (Kavale and Reese 1991). Although 73\% acknowledged that reading was the basic problem in most students categorized as LD, only $22 \%$ attributed the core deficit to linguistic processing. Endorsements of vague terms for the underlying nature of reading/learning disability included problems with "information processing," "memory," "attention," and "faulty learning strategies." Further, teachers surveyed believed we should teach to strengths, not deficits, and that teachers should enhance learning strategies. A specific orientation toward language-based remediation for children with language-based deficits was not endorsed.

As one might expect, the beliefs and practices of professors and other experts seem to reflect teachers' beliefs. Reynolds, Wang, and Walberg (1992) surveyed a broad field of over 100 "experts" in learning disabilities, including university faculty, to determine by consensus the requisite knowledge and skills that should distinguish teachers of children with learning handicaps. The most important aspects of remedial teaching valued by the experts consulted included such procedural basics as time on task, time spent in direct instruction on basic academic skills, provision of direct feedback, appropriate error correction, monitoring of task difficulty, and individualization. Although these principles of instruction are certainly important, mastery of structural language elements (phonemes, syllables, morphemes), the way they are represented in print, and how children learn them, were not designated as critical for teacher competence. It is thus easy to see why teachers may obtain certification without acquiring knowledge of the language content and processes critical to reading and spelling acquisition.

Encouraging this lack of content specificity are the noncategorical certification practices of more than half the states in the U.S. Teachers take three-hour courses such as "Teaching Students with Learning Problems" rather than specific and more extensive courses on the remediation of reading disability (Cranston-Gringas and Mauser 1992). Admittedly, categorical training programs giving certificates in learning disabilities and other handicaps have not been shown to benefit children with handicapping conditions more than non-categorical preparation (Marston 1987); however, their content may be no more specific than that of the general certification programs. Certi- 
ficate programs in learning disabilities usually do not require teachers to be experts in the way print corresponds to speech. At present, motivated teachers are often left to obtain specific skills in teaching phonology, phonetics, orthography, and other language skills on their own by seeking out workshops or specialized instructional manuals.

Professional organizations such as the International Reading Association (International Reading Association 1978) and the Division for Learning Disabilities of the Council for Exceptional Children have issued competency lists for teachers of children with reading/spelling difficulty to guide professional preparation, but these seem to contribute to the diffusion of teacher education. These lists usually include, among many other skills, a few competencies in understanding language development and language disorders, but not its specific relationships to reading, spelling, and writing. Typically there is no designated level of competence in knowledge of the oral and written language itself. Further, the lists of competencies are so extensive as to discourage intensive focus and study in depth (Anderson et al. 1985). The level of language knowledge necessary for teaching a person with language processing difficulties, however, exceeds what can be learned from casual or cursory training.

The limited phonemic awareness of teachers, their gaps in basic linguistic knowledge, and the difficulty with which the requisite information about language is gained have become apparent to this author through a series of teacher training experiences. Contrary to expectation, teachers do not display fully explicit awareness of spoken language structure and its relationship to writing just because they themselves are literate. Further, it has become clear that gaining the requisite information about linguistic structure takes time and effort. In fact, learning to appreciate and articulate the structure of spoken and written language challenges many adults despite (and perhaps because of) their own reading skill. Evidence for these conclusions was obtained from a survey given at the outset of a number of classes for teachers. The results of the survey presented here, shed light on which aspects of spoken and written language structure are often not well understood by teachers.

\section{Teachers' Knowledge of Linguistic Concepts}

\section{Survey of Background Knowledge of Language}

The information about teachers' background knowledge of language was obtained from a survey given to teachers at the 
first meeting of a course entitled Reading, Spelling, and Phonology. The data presented here was collected in six sections of this class. The survey was designed to assess the knowledge teachers have of speech sounds, their identity in words, correspondence between sounds and symbols, concepts of language, and presence of morphemic units in words. The survey assessed the specificity and depth of teachers' knowledge, in order to reveal misconceptions or unfocused concepts as well as outright absence of information. Teachers were asked to define terms, locate or give examples of phonic, syllabic, and morphemic units, and analyze words into speect sounds, syllables, and morphemes. The course the teachers were entering was designed to teach this material and by the conclusion of the class, most students had mastered it at a satisfactory level. The test is presented in table I :

\section{Table I}

Informal Survey of Linguistic Knowledge

(Answers are given in italics).

1. From the list below, find an example of each of the following: inflected verb compound noun bound root derivational suffix Answers impeached scarecrow phonograph nameless scarecrow nameless terrible phonograph impeached tables weakly

2. For each word on the left, determine the number of syllables and the number of morphemes:

$\begin{array}{lcc} & \text { Syllables } & \text { Morphemes } \\ \text { salamander } & 4 & 1 \\ \text { crocodile } & 3 & 1 \\ \text { attached } & 2 & 3 \\ \text { unbelievable } & 5 & 3 \\ \text { finger } & 2 & 1 \\ \text { pies } & 1 & 2 \\ \text { gardener } & 3 & 2 \\ \text { psychometrics } & 4 & 3\end{array}$

3. How many speech sounds are in the following words?

ox 


$\begin{array}{ll}\text { king } & 3 \\ \text { thank } & 4 \\ \text { straight } & 5 \\ \text { shout } & 3 \\ \text { though } & 2 \\ \text { precious } & 6\end{array}$

4. What is the third speech sound in each of the following words?

$\begin{array}{llll}\text { boyfriend } & |f| & \text { prayer } & |e| \\ \text { thankyou } & |\eta| & \text { higher } & |r| \text { or }|y| \\ \text { squabble } & |w| & \text { chalk } & |k| \\ \text { educate } & |y| \text { or }|y u| & \text { witchcraft } & |\vec{c}| \\ \text { stood } & |\mho| & \text { badger } & |j|\end{array}$

5. Underline the schwa vowels:

about melody sofa effect difficult definition

6. Underline the consonant blends:

doubt known first pumpkin squawk scratch

7. Underline the consonant digraphs:

wholesale psychic doubt wrap daughter think

8. When is a "ck" used in spelling? (immediately after a short, stressed vowel)

9. What letters signal that a " $\mathrm{g}$ " is pronounced $/ \mathrm{j} / ?(e, i, y)$

10. List all the ways you can think of to spell "long a": (a;ai;a-e;ey;ay; eigh)

11. List all the ways you can think of to spell $/ \mathrm{k} /:(c, k, c k, c h)$

Note: qu and $x$ also correspond to $[\mathrm{kw}] \&[\mathrm{ks}]$

12. What are six common syllable types in English?

(open, closed, $r$-controlled, vowel team, silent-e, consonant-le)

13. When adding a suffix to a word ending with " $y$ ", what is the rule?

(When a root word ends in a y preceded by a consonant, change $y$ to $i$ when adding a suffix except -ing. If the root word ends in a y preceded by a vowel, just add the suffix.)

14. How can you recognize a word of Greek origin?

(presence of $y$ for [I] as in gym; ch for [k] as in chorus; ph for [f] as in sphere; or a Greek combining form such as psych+ology)

15. Account for the double " $\mathrm{m}$ " in comment or commitment:

(The first $\mathrm{m}$ closes the syllable to make it short; com is a Latin morpheme as are ment and mit.)

\section{Subjects}

The teachers surveyed $(n=89)$ were a diverse group, educated at a variety of colleges and graduate schools and very 
experienced in classroom teaching. They included-in approximately equal distribution-reading teachers, classroom teachers, special education teachers, speech-language pathologists, classroom teaching assistants, and graduate students. The average length of time in teaching was 5 years, with a range of 0 to 20 years of experience. Subjects reported that they were, or were going to be, responsible for teaching language, writing, and/or reading to students from kindergarten to adulthood.

The teachers were also self-selected for participation in the class. The course was not required for certification or for any degree offered by the graduate education department at the college, so that most students enrolled out of interest in the topic and recognition of their own knowledge gaps. As a group, these students' written language skills were above average, judging from the quality of their written examinations and papers. They were among the more motivated and informed of professionals, and the results of the survey may therefore be overly optimistic as a reflection of teachers' knowledge in general.

\section{Survey Results}

The first survey of preexisting knowledge was given to 52 individuals, and a somewhat refined survey was given subsequently to another 37 subjects. The test revealed insufficiently developed concepts about language and pervasive conceptual weaknesses in the very skills that are needed for direct, language-focused reading instruction, such as the ability to count phonemes and to identify phonic relationships (table II).

Terminology. Descriptive terminology about morphology, such as inflection and derivation was foreign, as was the distinction between a compound and an affixed word form. Teachers were unaware of the difference between phonetics, phonology, and phonics, and although they had heard of phonological awareness, they themselves were typically unsure of the identity or number of component phonemes in words. Many subjects were unsure of what was meant by the term speech sound or phoneme, as they believed that letters were equivalent to speech sounds. (Refer to table I for correct answers to these and subsequent questions.)

Phonic Knowledge. Knowledge of phonics was surprisingly weak. Typically, about 10 to $20 \%$ of all subjects tested could consistently identify consonant blends in written words. Although they knew, for example that str was a blend, many also thought the tch in stretch and the bt in doubt were blends, because the concept of a blend as a representation of a spoken 
Table II

Percent of teachers who were successful on informal survey of linguistic knowledge $(n=52)$

Identified an inflection and inflected word form: $21 \%$

Identified the number of morphemes in a word: $27 \%$

Consistently identified consonant blends: $10 \%$

Consistently identified consonant digraphs: $0 \%$

Counted the number of phonemes in the following words:

ox (3) $25 \%$

straight (5) $39 \%$

king (3) $43 \%$

precious (6) $25 \%$

thank (4) $39 \%$

Identified the number of syllables in talked: $77 \%$

Identified schwa vowels in written words:

Explained when $c k$ was used:

$30 \%$

Explained the "y to i" rule:

$30 \%$

Knew six syllable types:

$15 \%$

Explained Greek spellings:

$10 \%$

Explained spelling of double $\mathrm{m}$ :

$20 \%$

consonant cluster was not differentiated from the occurrence of consonant letters adjacent in spelling. Almost no one in any group could reliably identify a consonant digraph. Less than half of those tested could identify the reduced vowel schwa consistently. Only $30 \%$ could explain when ck was used in spelling.

Phoneme and Morpheme Awareness. At the level of morpheme structure, only $27 \%$ of subjects were able to identify the component morphemes of transparent words. Many teachers remarked they had never been asked to analyze words at this level. Words with an indirect relationship between spelling and speech sounds were particularly difficult on the phoneme counting and phoneme identification tasks. Only $25 \%$ of this group knew that the word "ox" is comprised of three speech sounds, although it has only two letters ( $x$ corresponds to $/ \mathrm{k} / \mathrm{t} / \mathrm{s} /$ ). On a revised form of the pretest given to another 37 subjects, additional examples of the confusion between speech sounds and symbols were elicited by words whose spellings do not correspond directly to their speech sound constituents (table III).

When teachers were asked to isolate and pronounce specific speech sounds, they were typically unable to recognize the 


\section{Table III}

Percent of correct responses of second group $(n=37)$ of teacher/students to specific phoneme identification items

Identified the third speech sound in:

\begin{tabular}{ll} 
thank $(/ \eta /)$ & 10 \\
educate $(/ \mathrm{y} /$ or $/ \mathrm{yu} /)$ & 15 \\
squabble $(/ \mathrm{w} /)$ & 20 \\
higher $(/ \mathrm{y} /$ or $/ \mathrm{r} /)$ & 35 \\
prayer $(/ \mathrm{e} /)$ & 40 \\
stood $(/ \mho /)$ & 45 \\
witchcraft $(/ \check{c} /)$ & 55 \\
badger $(/ \check{\mathrm{j}} /)$ & 60 \\
chalk $(/ \mathrm{k} /)$ & 65 \\
boyfriend $(/ \mathrm{f} /)$ & 70 \\
\hline
\end{tabular}

nasal $/ \eta /$ (the final sound in sing), the glides / $w /$ and $/ y /$ when the spellings of words obscured their presence.

While the survey speaks for itself with regard to the linguistic misinformation held by many teachers, other misconceptions came to light in the course of class time and study. Among the more common were the belief that the letters "ng" represent an amalgam of $/ \mathrm{n} /$ and $/ \mathrm{g} /$; the belief that the letter $\mathrm{x}$ corresponds to $/ z /$; the belief that silent letters such as those in balk, calm, and comb should be pronounced; the belief that digraphs such as th represent a melding of two consonant phonemes $(/ \mathrm{t} /+/ \mathrm{h} /)$ rather than a unique phoneme; and the belief that a doubled consonant such as the t's in little represent two distinct speech sounds. With regard to spelling rules and conventions, ignorance was the norm. For example, few teachers could answer the final question in table I concerning why we double the $t$ in committed but do not double it in commitment.

\section{Discussion of Survey Results}

The results of this survey indicate that teachers who are literate and experienced generally have an insufficient grasp of spoken and written language structure and would be unable to teach it explicitly to either beginning readers or those with reading/spelling disabilities. Teachers commonly are misinformed about the differences between speech and print and about how 
print represents speech. Before elaborating on the importance of this knowledge for instruction, we should ask, why do such wide gaps in teachers' background knowledge exist?

The absence of previous coursework, although an obvious explanation, does not fully explain this phenomenon. First, there is evidence (Lindamood 1993) that complete and explicit awareness of phonemes in syllables is an underdeveloped metalinguistic skill in many people although they have learned to read. Phonological analysis skill appears to be distributed normally like many other language abilities. Lindamood also reported that those individuals who have trouble comparing the speech sounds in words tend to be those who are below average on tests of spelling ability. Thus, many average adults may have acquired linguistic awareness sufficient for basic reading though not sufficient to teach reading and spelling elements explicitly to children. Lindamood, and others, suggest that phonological analysis skill may be distributed normally, like many other language abilities. This variation, presumed to be intrinsic, appears to be relatively independent of intelligence.

In addition, many adults, even experienced teachers of reading and writing, conceptualize words in their written rather than their spoken form unless they are taught to pay attention specifically to speech sound structure. For example, when asked to count speech sounds in known words, they will count letters rather than phonemes (e.g., yellow will be viewed as having six speech sounds). Explicit phonemic awareness in many adults may even be limited because of their knowledge of print. Children who are first learning the alphabetic principle show in their creative spellings the capacity to analyze words phonetically (e.g., they will spell dragon as JRAGN and use as YUZ) (Treiman 1993). However, as they become familiar with print and as decoding becomes more automatic, children begin to judge what sounds are in words by their letters. Ehri (1984) showed that fourth graders are beginning to store words in their lexicons (mental dictionaries) as orthographic or written images. Once they could read, Ehri's elementary school subjects believed there is an extra $/ t /$ in ditch that is not present in rich, although only the initial consonants differ in these words. The adults surveyed in this study made similar judgement errors. They needed formal instruction and many examples to think beyond print while analyzing speech. Time and practice were needed to grasp concepts such as the identity of speech sounds, the nature of sound-symbol correspondence, the existence of minimally contrasting pairs of words in English (rich- 
ridge), historical changes in English spelling and pronunciation, and the organization of the English spelling system.

\section{Why is This Knowledge Important?}

Many teachers are charged with teaching children who have not been able to learn the written language as easily as they did, and whose primary disability in many cases resides in the realm of phonological processing and sensitivity to language structure. The teachers' content knowledge is critical to successful instruction because they can then chose what to teach, when, how and to whom. Some advantages of a good knowledge base include:

1. Being Able to Interpret and Respond to Student Errors. The error patterns of reading disabled and normal students reveal their awareness of spoken word structure and knowledge of the spelling system (Moats in press; Read 1986; Treiman 1993). For example, if a student repeatedly misspells consonant blends (DES/dress; SIK/silk), it is likely that the student is not consciously aware of the speech sounds that comprise the blends. A student who habitually substitutes voiced for voiceless consonants and vice versa (MAB/map; DRAK/drag) may not have attended to consonant voicing as a distinguishing feature of these consonants. Reading and spelling problems can be very specific to certain phonological and morphological word features (Moats 1993) and often respond best to instruction that addresses the source of a student's confusion.

2. Being Able to Pick the Best Examples for Teaching Decoding and Spelling. Concepts must be presented as clearly as possible for children with learning disabilities. For example, "short $\mathrm{e}^{\text {" }}$ and "short $i$ " are the most difficult vowel associations for many students to learn (Ehri, Wilce, and Taylor 1987); they are very close in place of articulation, there are only subtle articulatory cues to differentiate them, and the letter name " $e$ " is articulated in the same place as the "short $i$ " phoneme. Many learners cannot detect the differences or remember the symbols. An informed teacher can use the feel and look of the mouth, in addition to words chosen as examples, to teach these distinctions. In addition, certain key words will be better than others. Purer forms

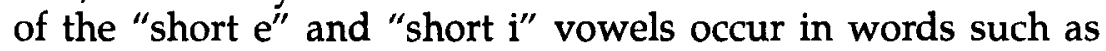
Eddy and itchy. In contrast, "short" vowels are distorted in pronunciation before the back consonants $/ \mathrm{k} /$ and $/ \mathrm{g} /$; the $/ \varepsilon /$ in egg is close to a "long a" in articulation, and the /I/ in igloo is close to a "long e." Thus words such as egg and igloo would be poor key words and should not be used as examples until stu- 
dents are secure with the sound-symbol relations in words with a more obvious correspondence.

3. Being Able to Organize and Sequence Information for Instruction. The informed teacher is able to impose an order or system onto linguistic information by classifying it and grouping it for instruction. For example, syllable patterns can be grouped into six types: closed, open, r-controlled vowel, silent-e vowel, vowel team, and consonant-le (Stoner 1985). The first two are easier to learn than the vowel team and r-controlled syllables, which should be taught later.

4. Being Able to Use Knowledge of Morphology to Explain Spelling. Teachers who are aware of the meaningful parts in words can teach students the reasons many words are spelled as they are. Accumulate has two $c^{\prime}$ 's because it is composed of a Latin prefix ( $a d$, which has become ac to fit the root beginning with $c$ ) and a root (cumulare). The word acute, in contrast, is one morpheme and there would be no reason to double the $c$. In other instances, knowing how a root word is spelled will help students remember derivations that are pronounced differently, such as magic and magician, differ and different, anxious and anxiety.

5. Being Able to Integrate the Components of Language Arts Instruction. The informed teacher can apply the principles of systematic, explicit instruction to the teaching of reading and spelling, and can do so flexibly. Instruction needs to be balanced and complete: while students are learning the code they also profit from learning to comprehend and compose (Adams 1990). With proper training, the teacher can integrate word study with meaningful reading and writing of text. Lincoln's Gettysburg Address, for example, is a goldmine for study of word derivation (dedicate-dedication; consecrate-consecration). Creative use of worthwhile texts lessens dependence on isolated instructional units, but is possible only when the teacher knows enough about language to exploit teaching opportunities.

\section{Evaluations by Teachers}

Acquiring the requisite content knowledge is a time-consuming, challenging process for a teacher candidate. The teachers who completed a semester of graduate study in lower level language processes and in how to teach them rated the content as "difficult" in comparison to other graduate education courses. Explicit and detailed knowledge of language organization was not learned simply through experience with speaking and with print; just as with children, teachers acquired it through study and practice. Some needed rather extensive work to develop 
phonemic awareness, as Lindamood (1993) predicts, and about $10 \%$ were not able to acquire that skill through a graduate course. Nevertheless, the teachers who completed the course were emphatic in their endorsement of the usefulness of the information in their teaching. Eighty-five to $93 \%$ of each class agreed that the information would be either highly useful or essential in their teaching, regardless of their specialty. Many commented that they should have learned the content before they started to teach, and $91 \%$ reported that such a course should be required for all teachers who are charged with teaching reading, writing, or language. How they would apply linguistic knowledge varied according to teachers' roles and philosophies of intervention, but they typically thought the knowledge would be useful in allowing them to interpret student errors, select examples wisely, explain sound-spelling relationships accurately, and logically organize instruction.

\section{Recommendations for Teacher Education}

In conclusion, several changes are recommended for the preparation of teachers responsible for teaching those with language-based learning difficulties.

To begin, our competency lists and licensing practices should state clearly that licensed teachers must themselves demonstrate phonemic awareness, have a working knowledge of the speech sound system, and know how our orthography represents spoken English. Moreover, the opportunity to learn this information in depth, through study of basic linguistics and application of the concepts in clinical teaching practice, must be part of every teacher training program in literacy education. Activities that promote such learning include discovering and classifying the speech sounds of the language, performing phonetic transcriptions, analyzing spelling errors, and completing phonemic awareness exercises. ${ }^{3}$ The concept of the morpheme and the principles by which words are constructed from meaningful units can be explored by dividing words, identifying derivational relationships, and studying word origin in English. Based on prior teaching experience, it seems that at least six weeks of study and practice must be devoted to these levels of language, using a linguistics text (e.g., Fromkin and

\footnotetext{
30ther concepts of speech production that have not been discussed here also need to be taught, such as coarticulation, articulatory salience, and the effect of prosody on the production of speech sounds. These concepts provide a framework for understanding why certain speech sounds are difficult to isolate, identify, and represent in spelling.
} 
Rodman 1993) and other material, before most teachers are secure with them. Even then, a few teachers and teacher-candidates will continue to show significant deficits in phonemic awareness that may severely limit their effectiveness. If possible, these individuals should be identified with reliable measures of phonological processing prior to their enrollment in a course of study, and the individuals counseled regarding the implications of their difficulty.

When language concepts are firmly entrenched, teachers are then ready to study English spelling and the manner in which it represents speech. The specific content of "phonics" should be learned (Hull 1985) but extended to include understanding of sound-symbol correspondences for both spelling and reading, syllable patterns and syllabication, and the effect of word meaning and word origin on spelling. This knowledge can then be applied to discovering error patterns in the work of students, designing lesson plans, critiquing published materials, and creating diagnostic instruments.

This type of course would be distinct in format and content from traditional introductory language courses taught in departments of communication science or speech-language pathology. Teachers would typically not find the emphasis on oral-written language relationships needed for reading/writing instruction in courses designed to train speech-language pathologists. The speech-language pathologist must be trained in specialty areas such as voice, articulation, and audiological problems, but the literacy educator must be an expert in reading and writing acquisition. Although the professional territory of both disciplines includes language knowledge, and some content would be common to the introductory training of both, the literacy educator needs coursework focused on literacy development. Nevertheless, a common understanding of language elements should enable greater interdisciplinary sharing to occur in the workplace.

Coursework encompassing lower level language organization (i.e., phonetics, phonology, morphology, sound-symbol correspondence) and how it is learned by beginning readers requires at least one semester; two would be preferable. It takes time for teachers to acquire knowledge of word structure and to adjust their views about the relationships between speech and print, even if they have the prerequisite linguistic analysis skills to do so. Other courses, of course, are needed to address topics in higher level language processing, including reading comprehension, written expression, and study strategies. 


\section{Summary}

Unfortunately, state certification practices, preservice teacher training, and the social contexts of schools do not adequately prepare reading and writing teachers for the demands of classroom practice. More specifically, neither undergraduate nor graduate training of teachers typically requires the command of language structure necessary to teach reading and spelling well. Consequently, teachers are inadequately prepared to teach emergent literacy, reading, and spelling to beginning readers and those encountering reading failure. The reasons for teachers' insufficient knowledge include the difficulty of the subject matter, the time required to learn it, and the absence of specific standards for training. Furthermore, speech sound awareness and understanding of orthography are elusive even for many literate persons, who may have intrinsic limitations in their linguistic sensitivity. In addition, many adults' concepts of language structure are so grounded in print that detailed awareness of speech is difficult to reactivate. This knowledge, once acquired however, can lead to better understanding of student errors, and to the ability to give corrective feedback, choose good examples, and create theoretically sound lesson plans.

Until we recognize that teachers do not naturally acquire the kind of expertise in language structure that is required of them for remediating and preventing reading problems, we will neglect to provide the necessary training. Teachers will continue to teach without understanding the alphabetic orthography and how it represents speech, will continue to give students misinformation, and will be unable to clarify concepts or to organize language instruction beneficially. Lower level language mastery is as essential for the literacy teacher as anatomy is for the physician. It is our obligation to enable teachers to acquire it.

\section{References}

Adams, M. J. 1990. Beginning to Read: Thinking and Learning About Print. Cambridge, MA: MIT Press.

Adams, M. J., and Bruck, M. 1993. Word recognition: The interface of educational policies and scientific research. Reading and Writing: An Interdisciplinary Journal 5:113-39.

Anderson, R. C., Heibert, E. H., Scott, J. A., and Wilkinson, I. A. G. 1985. Becoming a Nation of Readers: The Report of the Commission on Reading. Washington, D.C.: The National Institute of Education, U.S. Department of Education. 
Ball, A., and Blachman, B. 1991. Does phoneme segmentation training in kindergarten make a difference in early word recognition and developmental spelling? Reading Research Quarterly 26:49-66.

Billingsley, B. 1993. Teacher retention and attrition in special and general education: A critical review of the literature. Journal of Special Education 27:137-74.

Bowey, J. A., and Francis, J. 1991. Phonological analysis as a function of age and exposure to reading instruction. Applied Psycholinguistics 12:91-121.

Brady, S. 1986. Short-term memory, phonological processing and reading ability. Annals of Dyslexia 36:138-53.

Bryant, P. E., and Bradley, L. 1983. Psychological strategies and the development of reading and writing. In M. Martlew (ed.). The Psychology of Written Langauge: Developmental and Educational Perspectives. Chichester: Wiley.

Calfee, R. C. 1991. Decoding and spelling: What to teach? When to teach? How to teach it? Psychological Science 2:83-85.

Catts, H. W. 1989. Speech production deficits in developmental dyslexia. Journal of Speech and Hearing Disorders 54:422-28.

Chall, J. 1989. Learning to read: The great debate 20 years later: A response to "Debunking the great phonics myth." Phi Delta Kappan 70:521-38.

Cranston-Gringas, A., and Mauser, A. J. 1992. Categorical and noncategorical teacher certification in special education: How wide is the gap? Remedial and Special Education 13(4):6-9.

DeFries, J. C., Olson, R. K., Pennington, B. F., and Smith, S. D. 1991. The Colorado Reading Project: An update. In D. D. Duane and D. B. Gray (eds.). The Reading Brain: The Biological Basis of Dyslexia. Parkton, MD: York Press.

Ehri, L. C. 1984. How orthography alters spoken language competencies in children learning to read and spell. In J. Downing and R. Valtin (eds.). Language Awareness and Learning to Read. New York: Springer-Verlag.

Ehri, L. C. 1993. Development of the ability to read words: Update. In R. Ruddell, M. Ruddell, and H. Singer (eds.). Theoretical Models and Processes of Reading. Newark, DE: International Reading Association.

Ehri, L. C., and Robbins, C. 1992. Beginners need some decoding skill to read by analogy. Reading Research Quarterly 27:13-26.

Ehri, L. C., Wilce, L. S., and Taylor, B. B. 1987. Children's categorization of short vowels in words and the influence of spellings. Merrill-Palmer Quarterly 33(3):393-421.

Felton, R. H. 1993. Effects of instruction on the decoding skills of children with phonological-processing problems. Journal of Learning Disabilities 26:583-89.

Felton, R. H., and Wood, F. B. 1989. Cognitive deficits in reading disability and attention deficit disorder. Journal of Learning Disabilities 22:3-13.

Fromkin, V., and Rodman, R. 1993. An Introduction to Language. Fort Worth, TX: Harcourt Brace Janovich.

Gaskins, F. W., Downer, M. A., Anderson, R. C., Cunningham, P. M, Gaskins, R. W., Schommer, M., and The Teachers of the Benchmark School. 1988. A metacognitive approach to phonics: Using what you know to decode what you don't know. Remedial and Special Education 9:36-41.

Goswami, U. 1992. Annotation: Phonological factors in spelling development. Journal of Child Psychology and Psychiatry 33:967-75.

Goswami, U., and Bryant, P. 1990. Phonological Skills and Learning to Read. Hillsdale, NJ: Lawrence Erlbaum Associates.

Gough, P. B., Ehri, L. C., and Treiman, R., eds, 1992. Reading Acquisition. Hillsdale, NJ: Lawrence Erlbaum Associates.

Henry, M. 1993. Morphological structure: Latin and Greek roots and affixes as upper grade code strategies. Reading and Writing: An Interdisciplinary Journal 5:227-41.

Hull, M. 1985. Phonics For the Teacher of Reading. Columbus, OH: Charles Merrill. 
International Reading Association, Committee on Professional Standards and Ethics 1978. Guidelines for professional preparation of reading teachers. The Reading Teacher 32:48-55.

Juel, C. 1988. Learning to read and write: A longitudinal study of 54 children from first through fourth grades. Journal of Educational Psychology 80:437-47.

Kavale, K. A., and Forness, S. R. 1985. The Science of Learning Disabilities. San Diego: College Hill Press.

Kavale, K. A., and Reese, J. H. 1991. Teacher beliefs and perceptions about learning disabiliites: A survey of Iowa practioners. Learning Disability Quarterly 14:141-60.

Liberman, I. Y., and Liberman, A. M. 1990. Whole language vs. code emphasis: Underlying assumptions and their implications for reading instruction. Annals of Dyslexia 40:51-76.

Liberman, I. Y., and Shankweiler, D. 1985. Phonology and the problems of learning to read and write. Remedial and Special Education 6:8-17.

Lindamood, P. 1993. Issues in researching the link between phonological awareness, learning disabilities, and spelling. In G. R. Lyon (ed.). Frames of Reference for the Assessment of Learning Disabilities: New Views on Measurement Issues. Baltimore: Paul H. Brookes.

Lyon, G. R., Vaasen, M., and Toomey, F. 1989. Teachers' perceptions of their undergraduate and graduate preparation. Teacher Education and Special Education 12:164-69.

Marston, D. 1987. Does categorical teacher certification benefit the mildly handicapped child? Exceptional Children 53:423-31.

Mather, N. 1992. Whole language reading instruction for students with learning disabilities: Caught in the cross fire. Learning Disabilities Research and Practice 7:87-95.

Moats, L. C. 1993. Spelling error analysis: Beyond the phonetic/dysphonetic dichotomy. Annals of Dyslexia 43:174-85.

Moats, L. C. in press. Phonological spelling errors in the writing of dyslexic adolescents. Reading and Writing: An Interdisciplinary Joumal.

Moats, L. C., and Smith, C. 1992. Derivational morphology: Why it should be included in language assessment and instruction. Language, Speech, and Hearing Services in Schools 23:312-19.

Nolen, P. A., McCutchen, D., and Berninger, V. 1990. Ensuring tomorrow's literacy: A shared responsibility. Journal of Teacher Education 41:63-72.

Rack, J. P., Snowling, M. J., and Olson, R. K. 1992. The nonword reading deficit in developmental dyslexia: A review. Reading Research Quarterly 27:29-53.

Read, C. 1986. Children's Creative Spelling. London: Routledge and Kegan Paul.

Reynolds, M. C., Wang, M. C., and Walberg, H. J. 1992. The knowledge bases for special and general education. Remedial and Special Education 13(5):6-10.

Soodak, L. C., and Podell, D. M. 1993. Teacher efficacy and student problem as factors in special education referral. Journal of Special Education 27:66-81.

Stanovich, K. E. 1991. Cognitive science meets beginning reading. Psychological Science 2:70, 77-81.

Stoner, J. 1985. Syllable Plus. Cambridge, MA: Educators Publishing Service.

Treiman, R. 1992. The role of intra-syllabic units in learning to read and spell. In P. B. Gough, L. C. Ehri, and R. Treiman (eds.). Reading Acquisition. Hillsdale, NJ: Lawrence Erlbaum Associates.

Treiman, R. 1993. Beginning to Spell. New York: Oxford University Press.

Treiman, R., and Baron, J. 1983. Phonemic-analysis training helps children benefit from spelling-sound rules. Memory and Cognition 11:382-89.

Tunmer, W. E., and Hoover, W. A. 1993. Phonological recoding skill and beginning reading. Reading and Writing: An Interdisciplinary Journal 5:161-79.

Tunmer, W. E., and Nesdale, A. R. 1985. Phonemic segmentation skill and beginning reading. Journal of Educational Psychology 77:417-27. 
Vellutino, F. R. 1991a. Has basic research in reading increased our understanding of development of reading and how to teach reading? Psychological Science 2:70, 81-83.

Vellutino, F. R. 1991b. Introduction to three studies on reading acquisition: Convergent findings on theoretical foundations of code-oriented versus whole-language approaches to reading instruction. Journal of Educational Psychology 83:437-43.

Vellutino, F. R., and Scanlon, D. 1987. Phonological coding, phonological awareness, and reading ability: Evidence from a longitudinal and experimental study. Merrill-Palmer Quarterly 33:321-63.

Williams, J. 1987. Educational treatments for dyslexia at the elementary and secondary levels. In R. Bowler (ed.). Intimacy with Language: A Forgotten Basic in Teacher Education. Baltimore:The Orton Dyslexia Society.

Wolf, M., Bally, $H_{.}$and Morris, R. 1986. Automaticity, retrieval processes, and reading: A longitudinal study in average and impaired readers. Child Development 57 : 988-1000.

Yopp, H. K. 1992. Developing phoneme awareness in young children. The Reading Teacher 45:696-703.

Zigmond, N. 1993. Learning disabilities from an educational perspective. In G. R. Lyon, D. B. Gray, J. Kavanagh, and N. Krasnegor (eds.). Better Understanding Learning Disabilities: New Views From Research and their Implications for Education and Public Policy. Baltimore, MD: Paul H. Brookes. 